\title{
Fatigue crack propagation testing using subsized rotating bending specimens
}

\author{
C.S. Shin*, P.C. Chen \\ Department of Mechanical Engineering, National Taiwan University, No. 1, Sec. 4, Roosevelt Road, Taipei 10617, Taiwan, ROC
}

Received 18 June 2003; received in revised form 27 January 2004; accepted 6 February 2004

\begin{abstract}
In many industrial applications, mechanical properties characterization is needed yet sufficient amount of material for standardsized specimens is not available. Miniaturized specimen testing technique has to be employed. Currently there are a lot of effort in developing subsized specimen technique for impact, fracture toughness and tensile properties. Work on fatigue properties testing is limited and largely confined to stress/strain life tests. In the current work, evaluation of fatigue crack propagation behaviour using surface crack growth in a rotating bending rod has been attempted. Nine different rod geometries have been tested. The resulting fatigue crack propagation data is more sensitive to rod diameter than to rod length. Difference in crack growth behaviour can largely be understood when crack closure is taken into account. All in all, the crack propagation data obtained from these small sized rods agree well with those obtained from standard testing employing compact tension specimens. A more precise picture about the crack growth behaviour can be obtained if crack closure is considered. If crack closure is not monitored, rods with longer length and smaller diameter are more likely to give the conservative upper bound fatigue crack propagation behaviour.
\end{abstract}

() 2004 Elsevier B.V. All rights reserved.

\section{Introduction}

In many industrial applications, mechanical properties characterization is needed yet sufficient amount of material for standard-sized specimens is not available. For example, in the design and integrity assessment of nuclear reactor structural components, information on the degradation of various mechanical properties due to irradiation is needed. However, the available surveillance material is often highly limited. Similarly, during residual life assessment and extension of in-service structures such as power plant or chemical plant components, the current status of the mechanical

\footnotetext{
* Corresponding author. Tel.: +886-2-2362-2160; fax: +886-2-2362-2160.

E-mail address: csshin@ntu.edu.tw (C.S. Shin).
}

properties has to be evaluated from samples taken from these structures and compared with that of the virgin materials. Cutting samples from a structure invariably weaken it. Subsequent repair welding may help to alleviate the damage but it may also be a source of new defects and unfavorable residual stresses. Reduction of the volume of the sample cut for mechanical testing decreases the damage to the structure. On the other hand, for old plants, virgin material data are often non-existing or incomplete. Limited quantity of archive materials or sometimes the remnants of used specimens may be available. Both the newly cut samples and the archived remnants are often less than necessary for producing standard-sized test specimens. This has led to the development of miniaturized specimen testing technique (Corwin and Lucas, 1986; Corwin et al., 1993, 1997). Embrittlement is a major 


\begin{tabular}{|c|c|}
\hline \multicolumn{2}{|c|}{ Nomenclature } \\
\hline$a$ & semi-major axis of a surface crack (mm) \\
\hline$b$ & depth of a surface crack $(\mathrm{mm})$ \\
\hline B & deepest point of a surface crack \\
\hline $\mathrm{C}$ & $\begin{array}{l}\text { surface interception point of a surface } \\
\text { crack }\end{array}$ \\
\hline$\Delta K$ & $\begin{array}{l}\text { tensile portion of the applied stress } \\
\text { intensity range }\left(\mathrm{MPa} \mathrm{m}^{1 / 2}\right)\end{array}$ \\
\hline$\Delta K_{\text {eff }}$ & $\begin{array}{l}\text { effective stress intensity } \\
\text { range that the crack is open }\left(\mathrm{MPa} \mathrm{m}^{1 / 2}\right)\end{array}$ \\
\hline$L$ & rod length $(\mathrm{mm})$ \\
\hline$r$ & radius of a rod specimen $(\mathrm{mm})$ \\
\hline $2 S$ & arc-length of a surface crack $(\mathrm{mm})$ \\
\hline$\phi$ & rod diameter $(\mathrm{mm})$ \\
\hline
\end{tabular}

concern in the nuclear industry and a large body of literature is on the development of subsized Charpy $\mathrm{V}$-notch specimen for impact testing. A number of specimens and testing techniques have also been proposed for fracture toughness and tensile properties. Literature on fatigue properties testing in this respect is comparably scarce and mostly limited to stress/strain-life data evaluation. These included the reverse bending of TEM disk size specimens (Rao and Chin, 1993) and cyclic tensile test on miniature specimen (Nunomura et al., 1993). The ball indentation testing, developed primarily for flow properties evaluation (Haggag et al., 1990a,b), has been claimed to be able to correlate with the fatigue properties as well (Haggag et al., 1990b). For fatigue crack propagation, testing has mainly been confined to reduced size compact tension type specimens (Sriharsha et al., 1999). With this type of specimens, the amount of size reduction is limited as too small a specimen may lead to the interference of the grips. Strict demands on load application and measurement may also be placed upon the testing machines handling such specimens. In the current work, the possibility of using a small surface cracked cylindrical rod specimen for fatigue crack propagation measurement has been investigated. Conventional rotating bending machine with minimum modification of the grip to accommodate the small diameter rods will suffice the testing needs.

\section{Experimental procedures}

Cylindrical rod specimens with lengths $L=86,56$ and $43 \mathrm{~mm}$ and diameters $\phi=12,8$ and $6 \mathrm{~mm}$, giving a total of nine different size combinations, were machined from $12.5 \mathrm{~mm}$ diameter SK4 carbon steel rod stock. The chemical compositions of the material are listed in Table 1. Fig. 1 compares some specimens with different lengths and different diameters. In the following, the various rod specimens were named by their length and diameter combination (e.g., L86\$12). For each of the three lengths, a $15 \mathrm{~mm}$ space has to be reserved at either ends to allow for gripping. Accurate center alignment of the grips and specimen train is extremely important to avoid excessive vibration during high speed rotation testing. At the center of each rod specimens, a starter notch was created by electric-discharge machining using a thin circular copper foil electrode. For the $12 \mathrm{~mm}$ diameter rods, the starter notch has a depth of $1.8 \mathrm{~mm}$ and was created by a circular electrode $5 \mathrm{~mm}$ in diameter. The size of the starter notches in the smaller diameter rods were reduced proportionately.

Cyclic testing was carried out on a rotating bending machine. Suitable loading was applied through the use of dead weights in the form of four-point bending. The speed of rotation can be controlled by a rheostat. A maximum speed of $12,000 \mathrm{rpm}$ is achievable by the motor. However, the motor will have difficulty in driving at full speed when specimen deflection is heavy. Consequently, a speed of $7000 \mathrm{rpm}$, which can be comfortably achieved in all cases, was chosen for the tests.

Fatigue crack development on the rod surface was monitored using a $30 \times$ microscope. During the precracking stage, a stroboscope was employed to aid observation without stopping the machine. Once crack initiation was detected, the machine was stopped periodically. An angular micrometer was engaged at the free end of the specimen train. By locating the crack tips with the microscope while turning the specimen using the micrometer, the angle subtended by the crack on the rod surface can be recorded. In this way, the subtend angle can be measured to a resolution of $0.023^{\circ}$, which corresponds to a surface crack length of $2.4 \times 10^{-3} \mathrm{~mm}$ on a $\phi 12 \mathrm{~mm}$ specimen. Fig. 2 shows the experimental set up. In the analysis of the rod specimen crack growth data, the stress intensity 
Table 1

Chemical compositions of the materials employed for testing

\begin{tabular}{lllllllll}
\hline & $\mathrm{C}$ & $\mathrm{Si}$ & $\mathrm{Mn}$ & $\mathrm{P}$ & $\mathrm{S}$ & $\mathrm{Cr}$ & $\mathrm{Mo}$ & $\mathrm{V}$ \\
\hline SK4 rod stock & $0.90-1.00$ & $\leq 0.35$ & $\leq 0.85$ & $\leq 0.03$ & $0.05-0.08$ & $0.10-0.30$ & $\leq 0.03$ & $\leq 0.20$ \\
SK3 plate stock & $1.090-1.10$ & $\leq 0.35$ & $\leq 0.85$ & $\leq 0.03$ & $0.05-0.08$ & $0.10-0.30$ & $\leq 0.03$ & $\leq 0.20$ \\
\hline
\end{tabular}



Fig. 1. Rod specimens with different lengths and different diameters.

factor solution reported by Carpinteri et al. (1998) was adopted and only the tensile portion was used.

In order to assess whether these rod specimen results can reflect the standard fatigue crack propagation data, compact tension (CT) specimens $50 \mathrm{~mm}$ wide and $12 \mathrm{~mm}$ thick had also been employed. SK4 steel was not available in plate stock and the CT specimens had to be machined from a SK3 plate, which was of a slightly different composition (see Table 1) than the rod stock. To account for the possible variation in crack growth behaviour, a limited amount of rod specimens with length $86 \mathrm{~mm}$ and diameter $12 \mathrm{~mm}$ were also machined from the same plate stock to allow for comparison. Testing of the CT specimens was carried

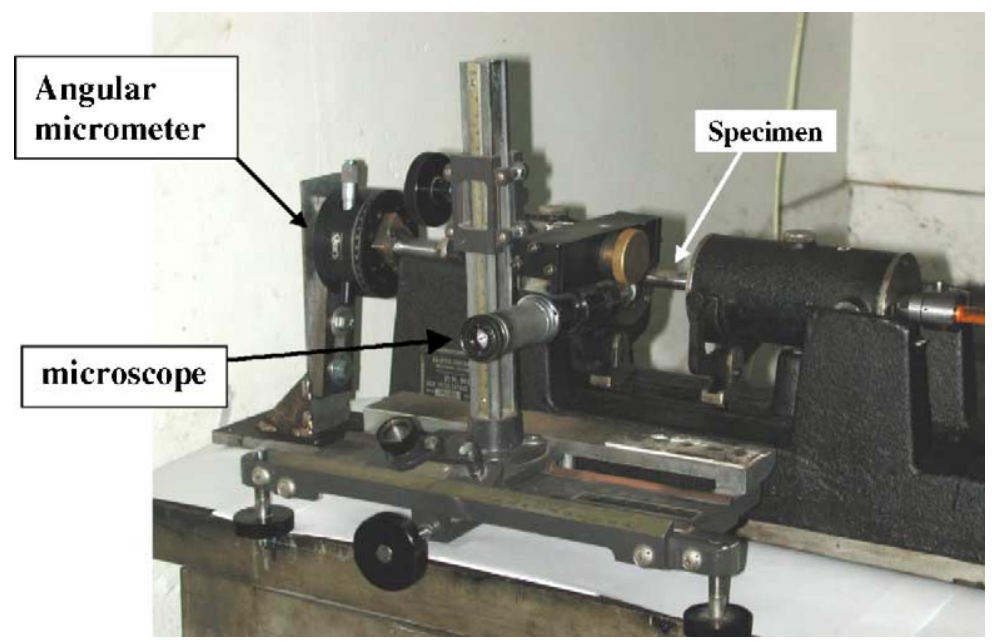

Fig. 2. Experimental set up. 
out using a servo-hydraulic machine at a frequency of $15 \mathrm{~Hz}$. Zero load level crossing was precluded as the CT specimens were loaded through pins. Thus, the load ratio ( $\mathrm{min} . l o a d / \mathrm{max} . l o a d)$ employed was 0.1 , in contrast with -1 in the rod specimens. If the volume of the CT specimen blank is $V$, the volumes of the largest and smallest rod specimens employed are $0.22 \mathrm{~V}$ and $0.03 \mathrm{~V}$, respectively.

\section{Results and discussion}

\subsection{Development of the crack shape}

Fig. 3 shows the nomenclature of the various dimensions of an elliptical surface crack in a rod. The stress intensity of such a crack is dependent on the crack depth ratio $b / r$ and the crack aspect ratio $b / a$ (Carpinteri et al., 1998). The surface measurement employed only revealed the surface arc-length $2 S$ of the crack. To establish an empirical relationship between the crack depth $b$ and the surface arc-length $2 S$, a number of calibration experiments had been carried out to grow cracks to various arc-lengths. These specimens were then broken open to allow the mapping of

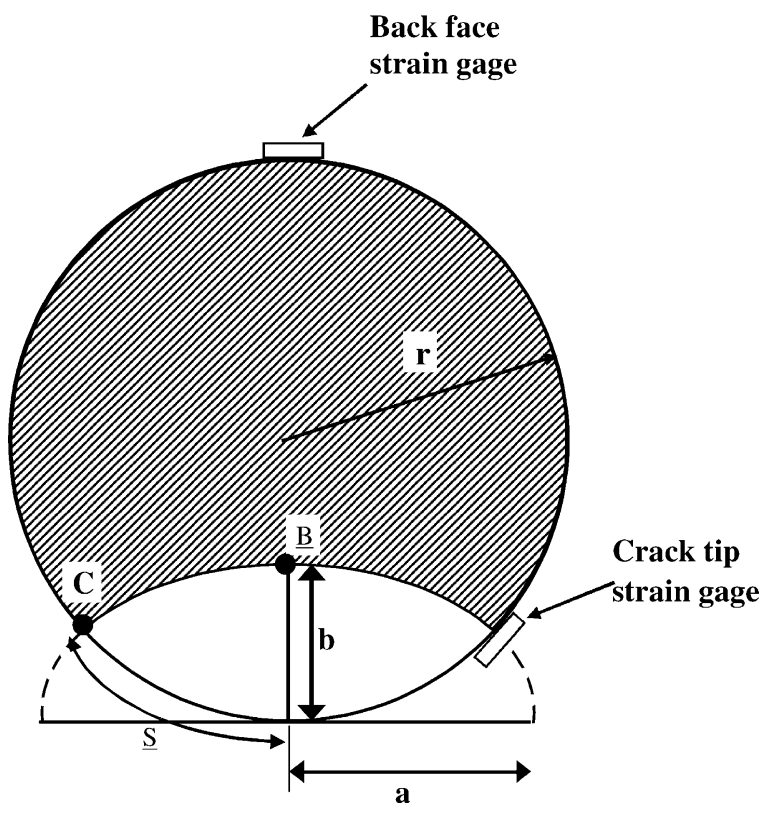

Fig. 3. Nomenclatures of the various dimensions of an elliptical surface crack in a rod. the instantaneous fatigue crack. Fig. 4 shows some of the typical fracture surfaces for the $\phi 12$ and $\phi 6$ rods. Fig. 5 presents the $b$ versus $2 S$ data for the nine rod sizes. It can be seen that for the same rod diameter, the $b-2 S$ data segregate onto the same scatter band which can be closely described by a straight line regardless of the rod length. Moreover, the $\phi 8$ and $\phi 6$ data fall on the same straight line. Crack shapes developed quite consistently and reproducibly in a self-similar manner in rods having the same diameter. The best-fit straight line to each diameter in Fig. 5 provides the empirical basis for deducing the crack depth in later experiments.

\subsection{Reproducibility of the crack growth data}

For each of the nine specimen configurations, at least six fatigue tests had been carried out. Of these some were interrupted at intermediate crack lengths to elucidate the $b-2 S$ relationships. At least two of the tests were carried through to completion to obtain the fatigue crack propagation data. Fig. 6 shows some typical results for two of the rod configurations. More results have not been included because they tend to crowd together with each other, as will be revealed in later sections. It can be concluded that testing under the same loading condition and specimen geometry gave consistent and reproducible results.

\subsection{Effect of rod length on crack growth}

Fig. 7a-c show the crack growth rate against the stress intensity range for different rod lengths grouped under the same rod diameters. For the $\phi 12$ specimens (Fig. 7a), the crack growth rate at the deepest interior point (B) is markedly higher than that at the surface point (C) under the same $\Delta K$. However, if we compare the corresponding surface and interior growth rates obtained at the same instant, the surface rate is slightly higher than the interior rate. The same phenomenon also occurs in other specimen diameters. This may presumably be due to the fact that for a particular crack geometry, the nominal stress intensity at the surface is higher. On the other hand, crack growth data at the same location segregate into a single scatter band regardless of the specimen lengths. Within these scatter bands, the L43 growth rates tend to be slightly higher than that of the longer specimens at the low 


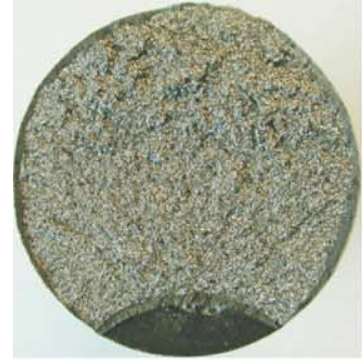

\section{L56 $\phi 12-2$}

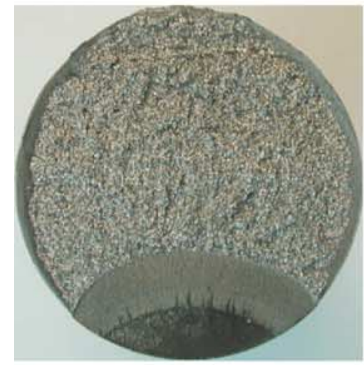

L43 $\phi$ 12-3

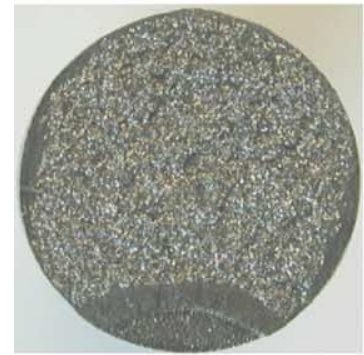

L43 $\phi$ 6-1

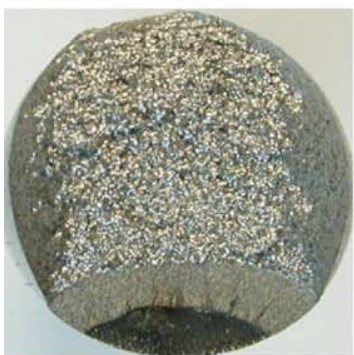

L86 $\phi 6-5$

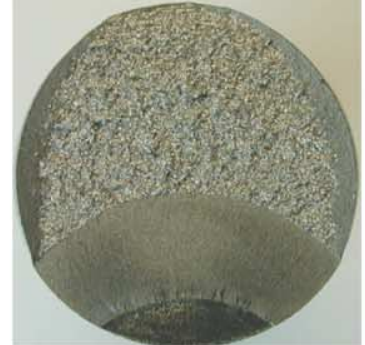

L86 $12-1$

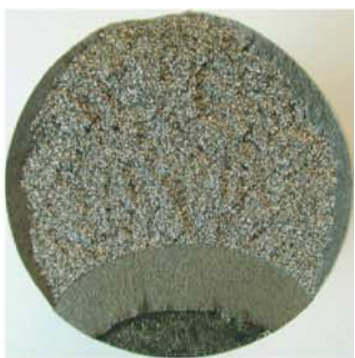

L56 $12-4$

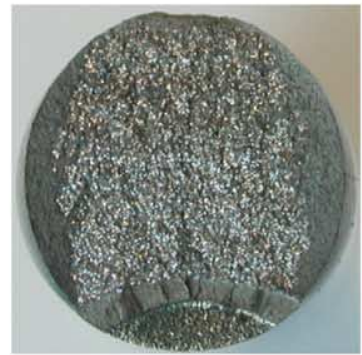

L56 $\phi$ 6-5

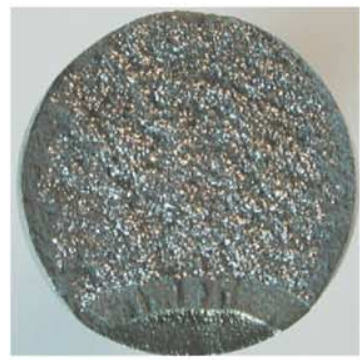

L86 $\phi$ 6-2

Fig. 4. Some typical fracture surfaces for the $\phi 12$ and $\phi 6$ rods. 


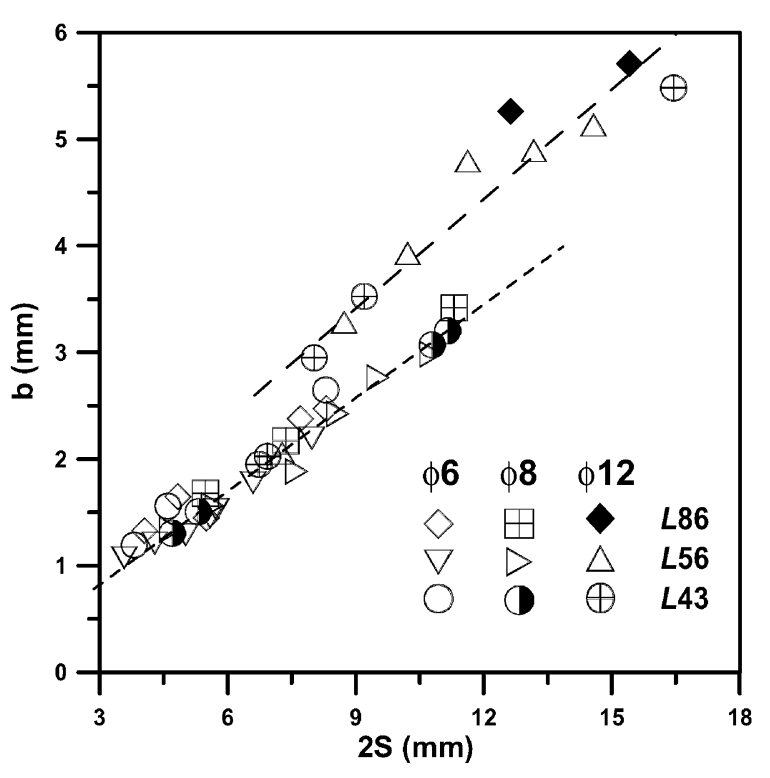

Fig. $5 . b$ vs. $2 S$ data for the nine rod geometries.

stress intensity end. However, the discrepancy is of comparable order as the test to test variation shown in Fig. 6.

In the $\phi 8$ results (Fig. $7 b$ ), surface and interior growth behaviour no longer segregate into two distinct groups. Surface and interior growth rates from all specimen lengths fall roughly into a loose scatter

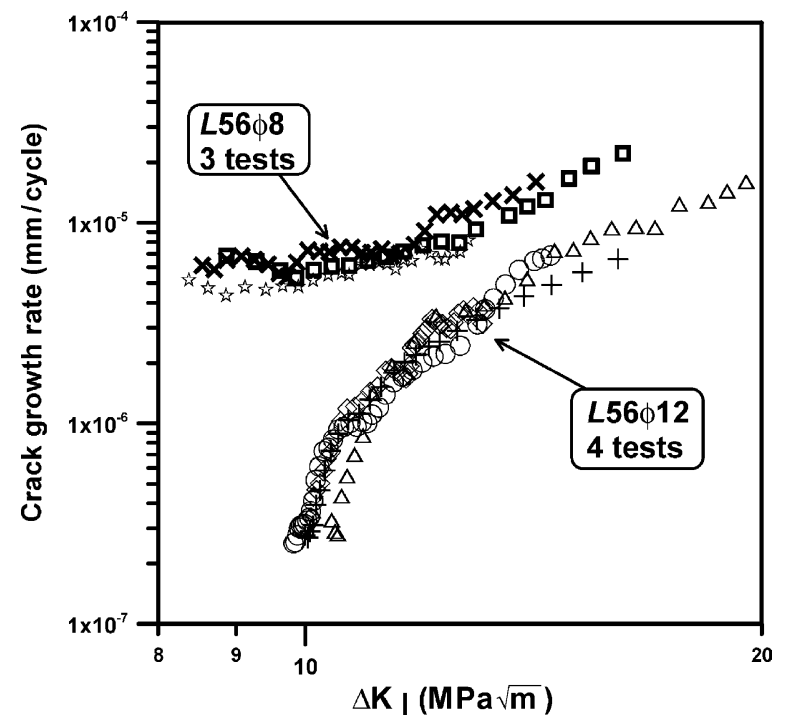

Fig. 6. Typical reproducibility of surface crack growth behaviour of two rod geometries. band. This band merges into a narrow line at $\Delta K$ above $15 \mathrm{MPa} \mathrm{m}^{1 / 2}$ but has wider scatter at the low stress intensity end. At this end, shorter specimens tend to grow slightly faster. Also the surface rates are also marginally higher than the interior rates when compared under the same $\Delta K$ here. Part of these differences may be experimental scatter in the $b-2 S$ relationships and part of these may be related to problems in the stress intensity. More discussion on these differences will be made in a later section.

For the smallest diameter $\phi 6$ specimens (Fig. 7c), the surface rates are again slightly higher than the interior rate under the same $\Delta K$ as in the $\phi 8$ case. The growth behaviour of the longest L86 specimens is the same as that of the L56 specimens. Crack growth rates of the shortest L43 specimens are slightly lower than that of the other two lengths. All in all, crack growth behaviour in the rod specimens under rotating bending is not very sensitive to rod length except for the shortest specimens in the smallest diameter (L43ф6).

\subsection{Effect of rod diameter on crack growth}

Fig. 8a-c show the crack growth behaviour for different rod diameters grouped in terms of the rod lengths. For the L86 specimens (Fig. 8a), crack growth behaviour segregates into three groups. The $\phi 6$ specimens grew with the highest rates. The $\phi 12$ surface growth is the slowest. The $\phi 8$ and the $\phi 12$ interior growth behaviour fall onto the same band and have intermediate rates. The difference between the highest and intermediate rate groups is getting smaller as $\Delta K$ increases. Unfortunately, growth behaviour at higher $\Delta K$ has not been obtained for the L86 $\phi 6$ specimens because a higher loading/ $\Delta K$ will cause unacceptable deflection that will trip off the testing machine.

For the L56 specimens (Fig. 8b), segregation of growth behaviour into three groups is not so prominent as in the above case. The $\phi 6$ data, though still consistently higher than the others, are not significantly different from the $\phi 8$ data as that in the L86 specimens. As a result, the $\phi 6, \phi 8$ and the $\phi 12$ interior behaviour roughly fall into a loose scatter band. The $\phi 12$ surface growth is still at the same distance below that of the others.

Like that in the former two cases, the $\phi 12$ surface growth of the L43 specimens (Fig. 8c) is markedly slower than the other data. The $\phi 6$ data has merged 

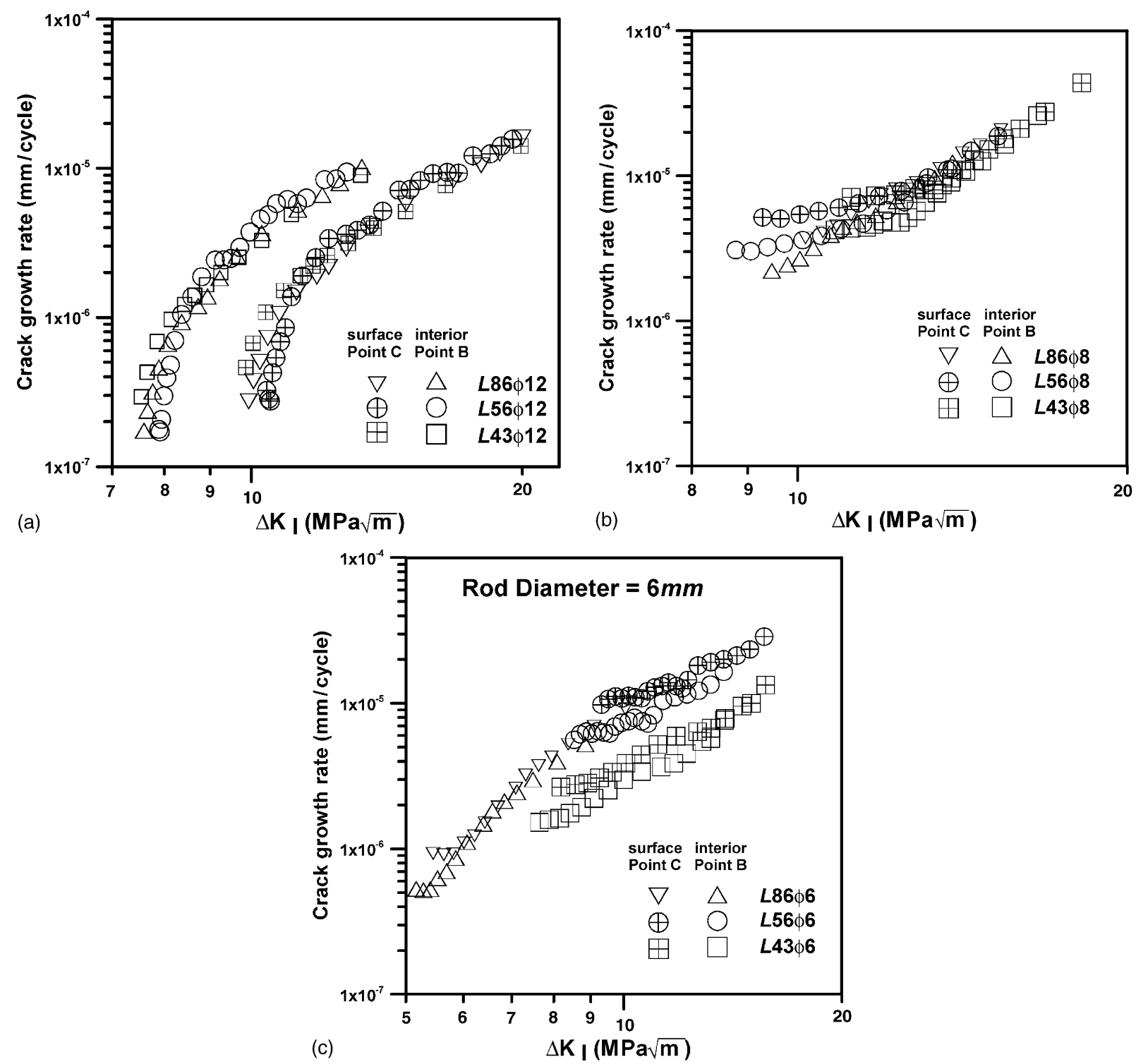

Fig. 7. Crack growth rate against the stress intensity range for (a) $12 \mathrm{~mm}$, (b) $8 \mathrm{~mm}$, (c) $6 \mathrm{~mm}$ diameter rods of different lengths.

well into the scatter band of the $\phi 8$ and $\phi 12$ interior growth rates. A subtle difference is evident at the low stress intensity end of this group of data: the $\phi 12$ growth has dropped steeply into the near threshold regime while that of the $\phi 8$ and $\phi 6$ growth still remains in the Paris law regime. This makes the $\phi 8$ and $\phi 6$ growth rates significantly higher than that of the $\phi 12$ growth rates at $\Delta K<9 \mathrm{MPa}^{1 / 2}$. In fact, this phenomenon can also be discerned in the L56 case in Fig. $8 b$.

All in all, crack growth behaviour is more sensitive to rod diameter than rod length. Nevertheless, above $\Delta K=10 \mathrm{MPa} \mathrm{m}^{1 / 2}$, it seems that using rod diameters from 6 to $12 \mathrm{~mm}$ for different rod lengths gives similar crack growth results except for the surface growth of the $\phi 12$ rods. 

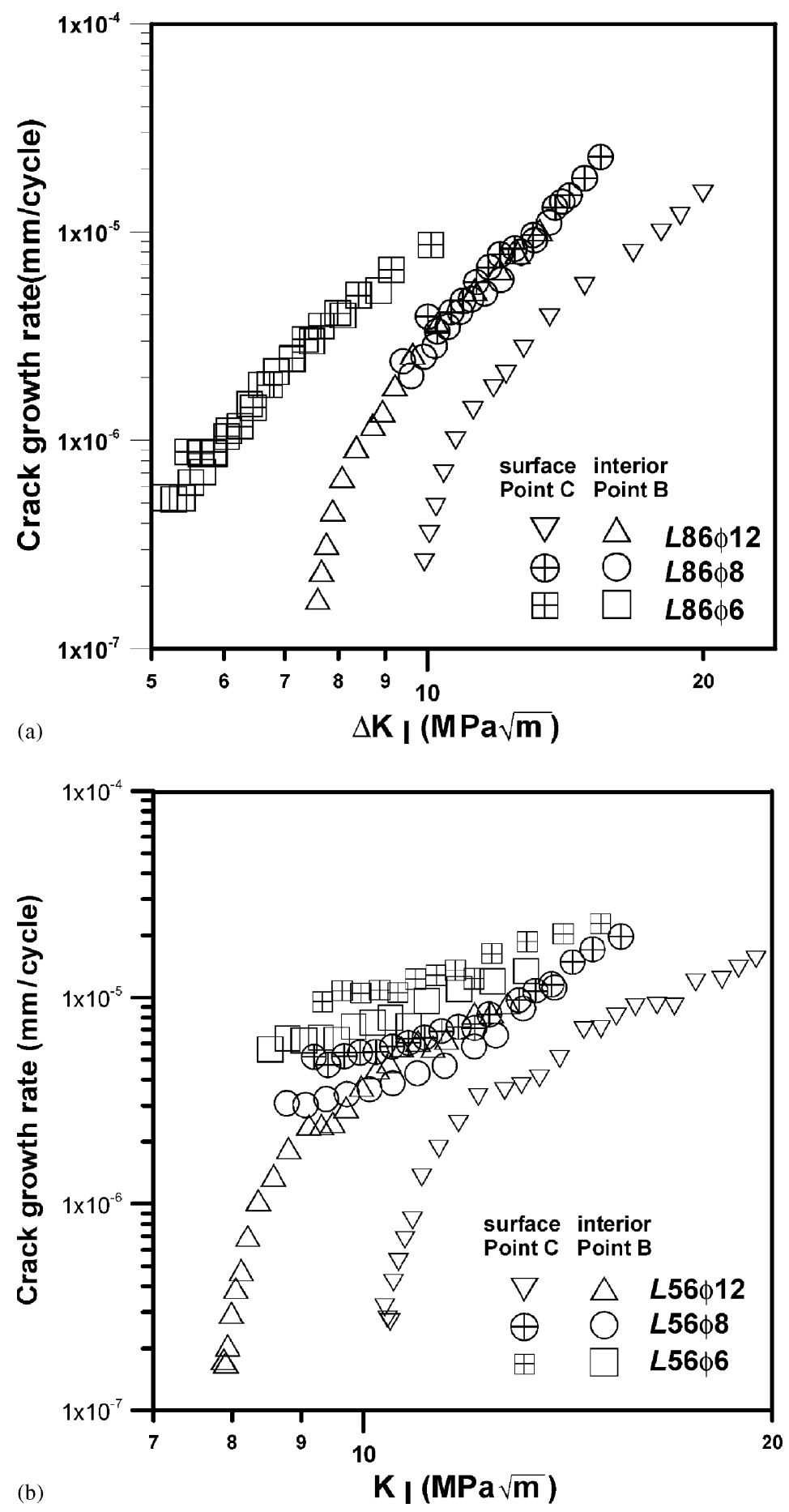

Fig. 8. Crack growth behaviour against the stress intensity range for (a) $86 \mathrm{~mm}$, (b) $56 \mathrm{~mm}$, (c) $43 \mathrm{~mm}$ long rods of different diameters. 


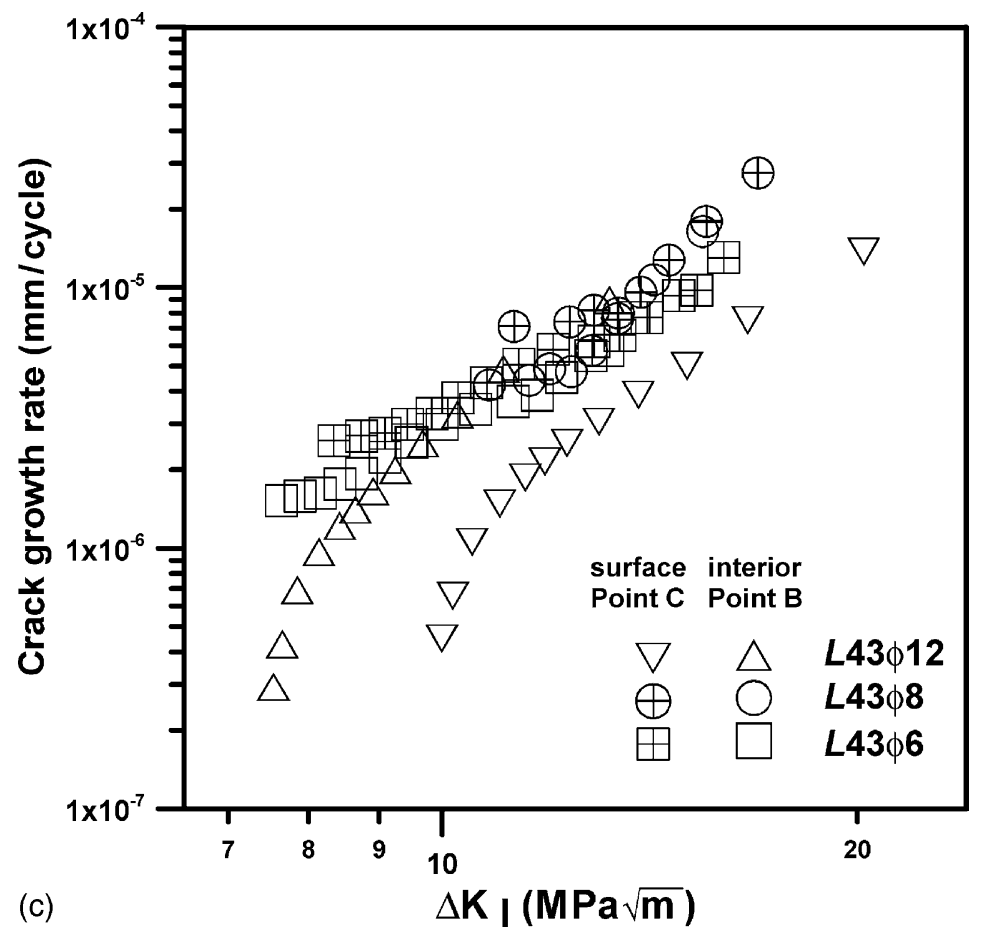

Fig. 8. (Continued).

\subsection{Difference between interior and surface crack growth}

In the above discussion, it is clear that the crack growth rates in the $\phi 12$ specimens are much higher in the interior than on the surface under the same stress intensity. If compared under the same crack growth rate, the surface stress intensity ranges are about $25-40 \%$ higher than that at the deepest interior point B. Such amount of difference persists at different growth rates. By contrast, in the $\phi 8$ and $\phi 6$ specimens, the surface growth is slightly faster than that in the interior at low stress intensities. At higher stress intensity ranges, no significant difference between surface and interior growth behaviour exists. Possible explanation for this discrepancy may lie on the validity and accuracy of the stress intensity factor and the difference in crack closure behaviour.

It has been pointed out that at the surface interception points of a semi-elliptical crack, the $1 / \sqrt{ } r$ singularity leading up to the $K$-dominant field in general does not exist (Benthem, 1977; Bazant and Estenssoro, 1979). The validity of using $\Delta K$ to correlate the fatigue crack growth rate here with that at positions where a $K$-dominant field exists is questionable. However, this complication does not exist at a little distance below the surface. This problem has been addressed by Carpinteri et al. (1998) and the stress intensities were reported up to a near surface point only. In the current work, an operational $\Delta K$ for the surface interception point $C$ was obtained by using a quadratic extrapolation to the reported stress intensity solution in Carpinteri et al. (1998). In a recent analysis of surface crack growth in rods under tension (Shin and Cai, 2004), such extrapolated stress intensity values tend to be lower than the experimentally deduced stress intensity at the surface. The discrepancy depends on the crack aspect ratio and crack depth and the maximum error is about $10 \%$. Incidentally, examination of the $\phi 8$ and $\phi 6$ cases (Fig. $7 b$ and c) revealed that under the same crack growth rate, the surface stress intensity is $\sim 10 \%$ lower than the stress intensity at the interior point $\mathrm{B}$ at low growth rates. Thus, the slight difference between surface and interior behaviour in the $\phi 8$ and $\phi 6$ specimens may be attributed to this error. However, the difference between 
surface and interior growth in the $\phi 12$ specimens is much larger and cannot be explained by validity and accuracy issue of the stress intensity solution alone.

Regarding the crack closure phenomena, works on part-through cracks showed that the degree of crack closure is heavier on the surface than in the interior (Fleck et al., 1983; Ray et al., 1987). Thus, under the same nominally applied stress intensity, the effective crack driving force is higher in the interior. This corroborates with the trend shown in Fig. 7a that the interior growth is faster than that on the surface. Crack closure in a metallic specimen is readily and accurately measured using the compliance technique (Fleck, 1988). This technique has been employed here. A strain gage straddling the crack at the tip region was used to reflect the crack closure on the surface. A back face gage, sticking opposite the crack as shown in Fig. 3, was used to reflect the bulk closure. This bulk closure may be more representative of the closure behaviour in the interior (Fleck et al., 1983; Fleck, 1988). Intermittent measurement using this technique as the crack grew along proved to be difficult as the lead wire got wound up in the rotating bending setup. Consequently, only a pair of closure data at one crack length has been taken in one of the L86\$12 specimens for comparison. In Fig. 9, the open symbols represent the crack growth rate correlated in terms of the whole tensile part of the applied stress intensity range $(\Delta K)$. The two black symbols represent the crack growth correlated in terms of the effective stress intensity range $\left(\Delta K_{\text {eff }}\right)$. The latter is defined as the maximum stress intensity minus the stress intensity at which the crack started to close as indicated by the compliance changes. It is clear that the surface and interior growth behaviour falls in line with each other when crack closure has been taken into account.

Such a measurement had not been made in the $\phi 8$ and $\phi 6$ specimens because the available space was not enough to accommodate two strain gages. In fact, with the much smaller net section areas in these specimens, one would expect less difference between the degree of surface and interior crack closure. This may probably be the reason for similar crack growth behaviour on

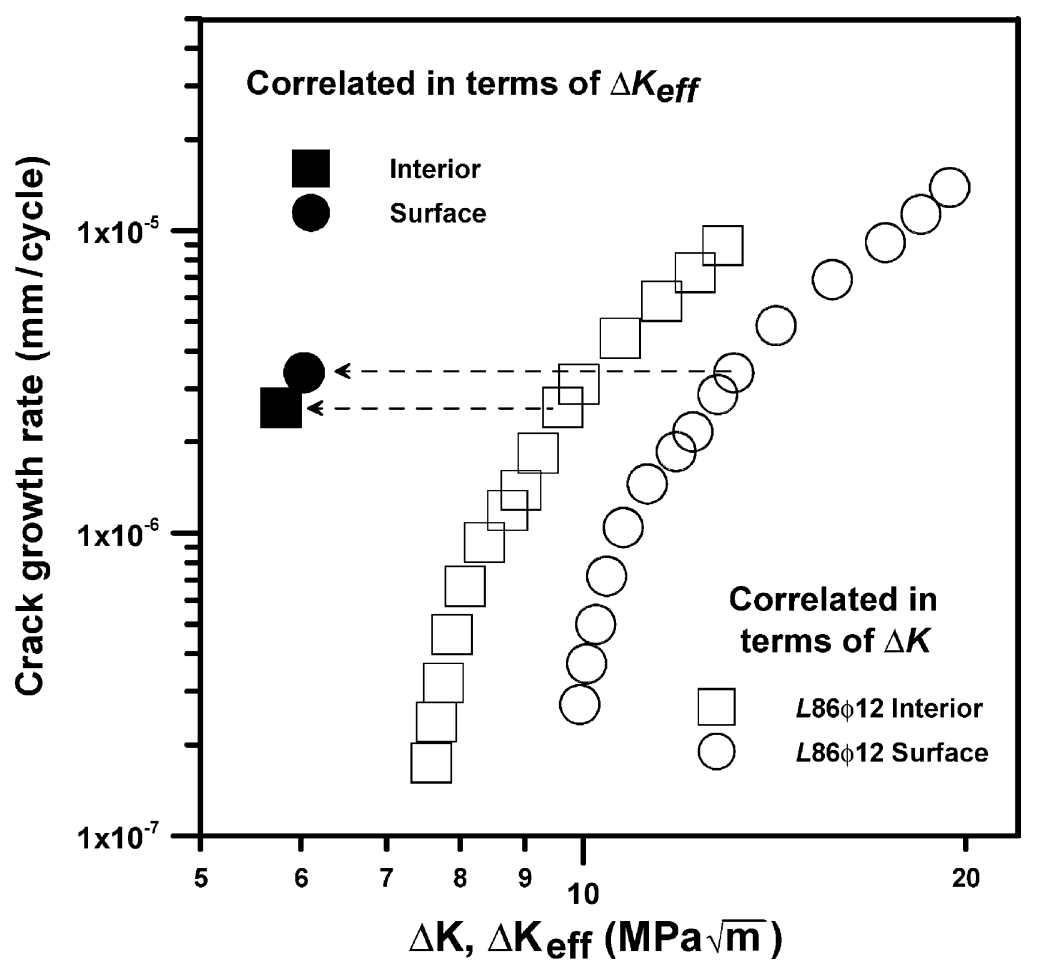

Fig. 9. Surface and interior crack growth rate for L $86 \phi 12$ correlated in terms of $\Delta K$ (open symbols) and $\Delta K_{\text {eff }}$ (black symbols). 
the surface and the interior for the smaller diameter specimens.

Crack opening displacement will be enhanced by larger deflection and/or smaller net section area. Thus, the cracks in the $\phi 6$ and $\phi 8$ specimens are likely to stay open for a larger part of the loading cycle and grow faster than that in the $\phi 12$ specimens. Similarly, for the same specimen diameter, the duration of crack opening will increase with specimen length as the latter will promote deflection. This line of reasoning may explain the phenomenon pointed out above in Fig. 8c, namely, the initial growth in the $\phi 12$ specimen fell in the near threshold regime while that in the $\phi 6$ and $\phi 8$ specimens, which had a higher $\Delta K_{\text {eff }}$, remained in the Paris' law regime. As crack grew, specimen deflection increased and the net section area decreased. The cracks would move closer towards fully open during the tensile phase and so crack growth behaviour tended to merge together at larger crack sizes (which correspond to higher $\Delta K$ in Figs. 7 and 8 under constant loading amplitude). This line of reasoning suggests that to stay by the conservative side, longer rods with smaller diameters should be used as they will tend to give upper bound growth rates which are less affected by crack closure.

\subsection{Comparison with CT specimen results}

The load ratio (min.load/max.load) employed for the CT specimens was 0.1 , while that in the rod specimens was -1 . In the following calculation of nominal $\Delta K$, all the applied loading range has been used for the CT specimens while only the tensile portion was taken in the rod specimens. Due to the vastly different load ratio, difference in crack closure responses in the two kinds of specimens is expected.

Fig. 10 compares the crack growth of rod specimens machined from the rod stock and the plate stock, as well as that of the CT specimens. Like that in the specimen from the rod stock, the plate stock rod specimen shows a distinctly slower growth rate at the surface than at the interior. Under the same $\Delta K$, the growth rate in the plate stock rod is slightly but consistently higher than that in the corresponding position in the rod stock rod. For the CT specimens, the CT1 and CT2 data were measured under constant amplitude loading.

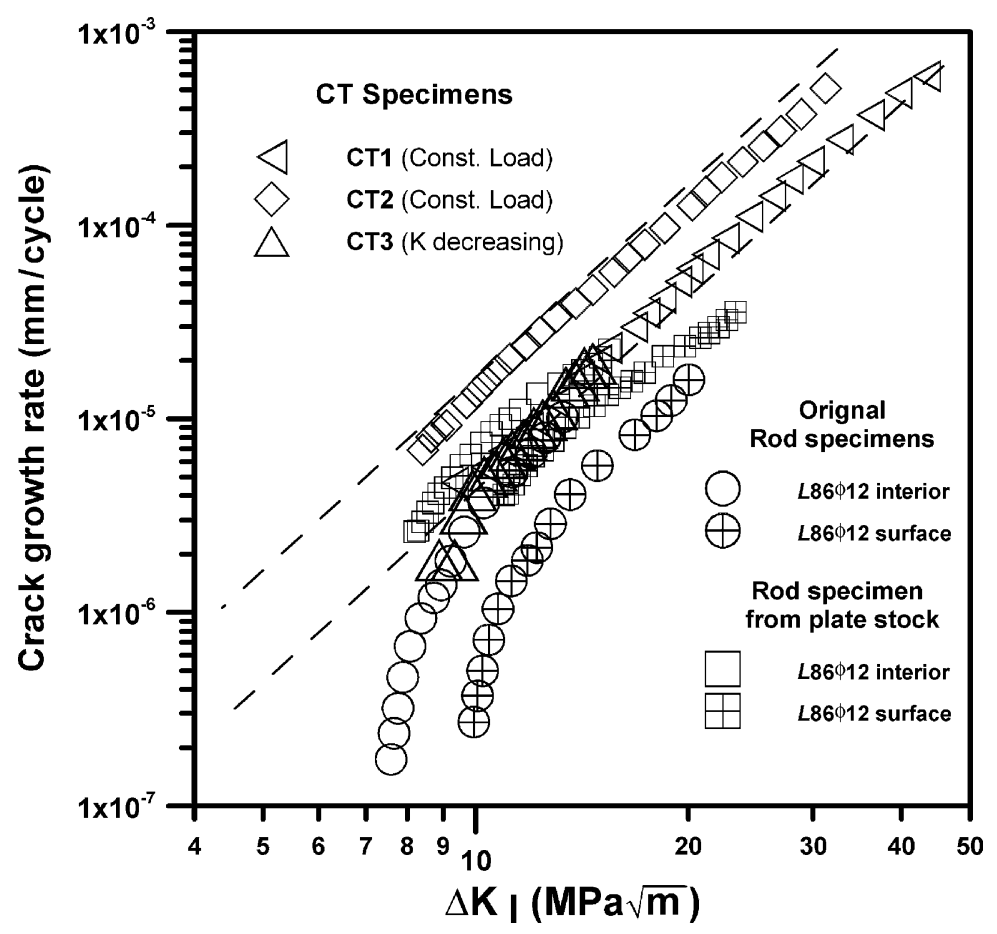

Fig. 10. Comparison of rod stock and plate stock rod specimen data with the CT specimen data. 


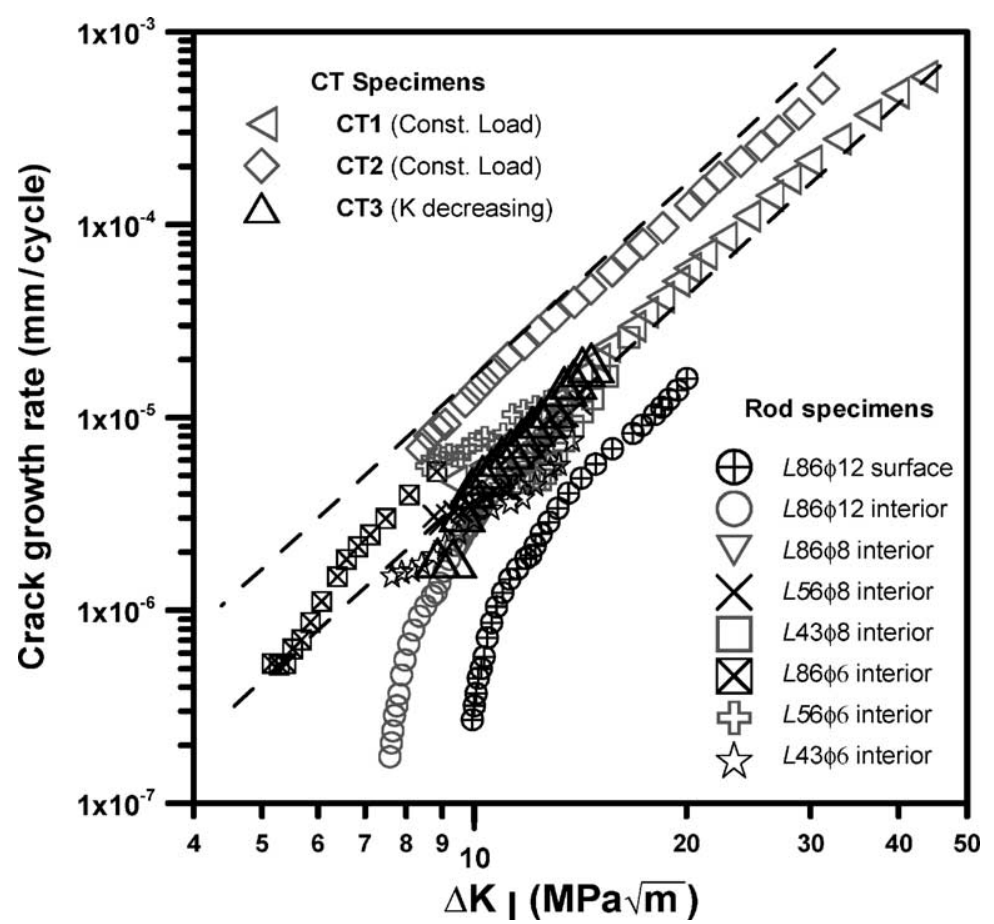

Fig. 11. Comparison of all typical rod specimen data with the CT specimen data in terms of $\Delta K$.

The CT3 data were from a $\Delta K$ decreasing test carried out using manual load shedding. The dotted lines enveloped the scatter band of the CT specimen growth data in the Paris' law regime. Crack growth starts to depart from this band into the near threshold growth at a rate $\sim 3 \times 10^{-6} \mathrm{~mm}$ per cycle. The interior growth of the plate stock rod also lies inside the CT scatter band while the surface growth is slightly slower and falls outside the scatter band.

Fig. 11 puts all the representative rod specimen data and the CT specimen data together. Bearing in mind that to adjust for the difference between the plate stock and the rod stock, the CT scatter band should be displaced slightly to the right. If such shifting is made, most of the rod data will fall inside the CT band. The only exception is the L $86 \phi 12$ surface growth, which is typical of all $\phi 12$ surface growth behaviour and it falls slightly below the main stream scatter band. Also, at growth rates below $\sim 3 \times 10^{-6} \mathrm{~mm}$ per cycle, the rod data tend to deviate from the scatter band as they started to enter the near threshold growth regime. This agrees with the near threshold growth of the CT3 data.
Fig. 12 compares the L86 $\$ 12$ surface and interior growth rate with the $\mathrm{CT}$ results in terms of the effective stress intensity range $\Delta K_{\text {eff }}$. When taking into account the crack closure phenomenon, the L86\$12 surface and interior growth falls in line with the CT results. Although crack closure data for the rod specimens are limited, it seems likely that the discrepancies displayed in Fig. 11 mentioned above may largely be attributable to the difference in the degrees of crack closure in different specimens.

As a conclusion, by choosing the right rod dimensions, growth data from small sized rod specimens can faithfully reflect that of the standard specimen results. A more precise picture about the crack growth behaviour can be obtained if crack closure is taken into account.

\subsection{Limitations of the rod specimen and possible improvement}

The current set-up can provide useful fatigue crack growth information using much less material than that required in a standard test. The amount of material 


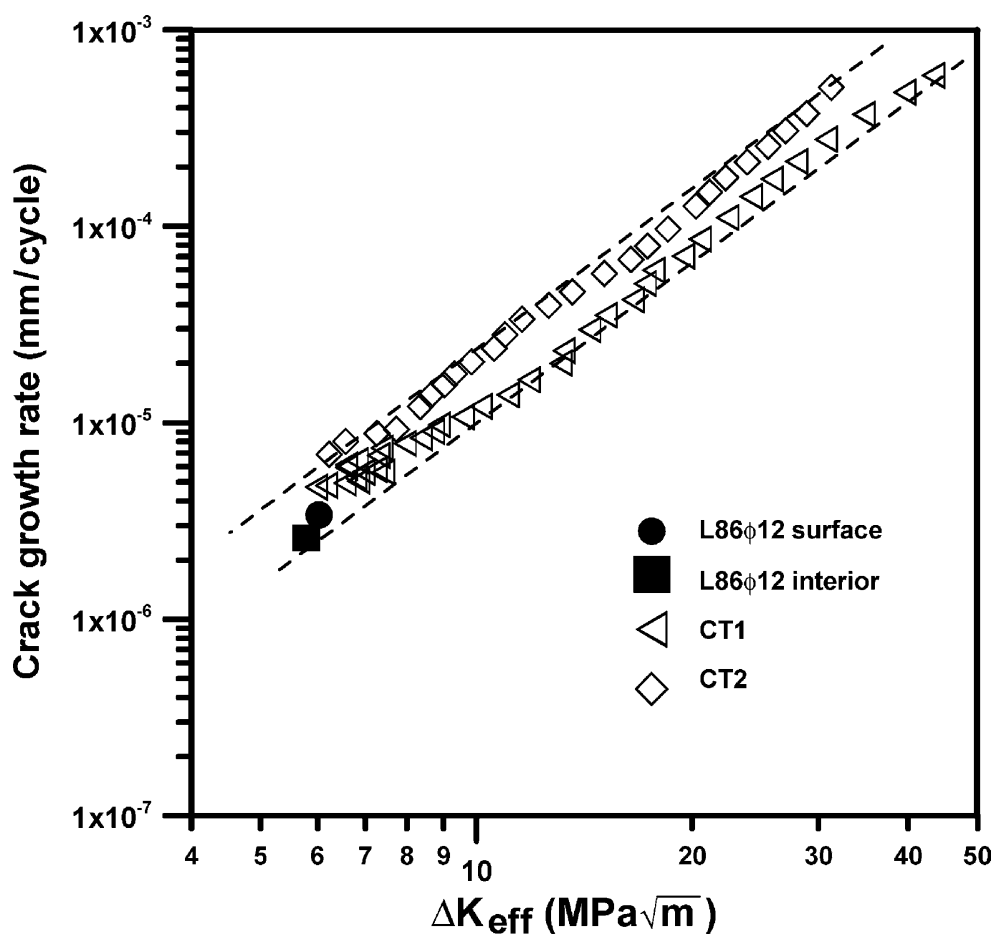

Fig. 12. Comparison of the L86\$12 surface and interior growth rate with the CT results in terms of the effective stress intensity range $\Delta K_{\text {eff }}$.

needed can be further reduced if specimen reconstitution technique (Nishiyama et al., 1998; Viehrig and Boehmert, 1998; De Backer and Gutierrez-Solana, 1998) is employed. Remnant impact specimens are well suited to the size range used in this work. It is economical and fast $(>100 \mathrm{~Hz})$. However, there are several limitations in the current setting. Firstly, the largest loading applicable is limited by the accompanying excessive deflection in the rotating bending setup. This limit the maximum $\Delta K$ and growth rate achieved. Secondly, it is extremely troublesome and impracticable to monitor crack closure in a rotating specimen. Yet closure information is helpful for a better grasp of the crack growth behaviour. Thirdly, automation of testing is not easy. Conventional automated crack length measurement methods are difficult to apply under the rotational setting. Lastly, the load ratio of rotating bending is confined to -1 . These limitations can be overcome, at the expense of cost and speed of testing, by employing an axial tension version of the same surface cracked rod specimens. Work in this direction has been underway (Shin and Cai, 2004).

\section{Conclusions}

Fatigue crack propagation testing has been carried out on nine different sizes of surface cracked rod specimen using rotating bending. A number of observations can be drawn:

(1) Crack growth behaviour in the rod specimens under rotating bending is not sensitive to rod length except for the shortest ( $43 \mathrm{~mm}$ long) specimens with the smallest diameter $(6 \mathrm{~mm})$, which exhibited a slower rate than the longer rods with the same diameter.

(2) For the $12 \mathrm{~mm}$ diameter rods, surface crack growth was markedly slower than that at the interior. For diameters equals $8 \mathrm{~mm}$ or smaller, no significant difference between surface and interior growth was observed.

(3) Under the same rod length, crack growth in the smallest diameter specimen was higher than that in larger diameters. The difference decreased with rod length and disappeared in the $43 \mathrm{~mm}$ rods. On the other hand, the surface growth in all the $12 \mathrm{~mm}$ 
diameter rods is the slowest among different diameter rods in every specimen length tested.

(4) The above discrepancies in growth behaviour may probably be explained in terms of difference in the degree of crack closure.

(5) Crack growth data from the rod specimens basically fall in line of the scatter band of the standard specimen data.

\section{Acknowledgements}

The authors are grateful to the National Science Council, ROC for supporting the work through the project NSC91-2212-E-002-030.

\section{References}

Bazant, Z.P., Estenssoro, L.F., 1979. Surface singularity and crack propagation. Int. J. Solids Struct. 16, 405-426.

Benthem, J.P., 1977. State of stress at the vertex of a quarterinfinite crack in a halfspace. Int. J. Solids Struct. 13, 479-492.

Carpinteri, A., Brighenti, R., Spagnoli, A., 1998. Surface flaws in cylindrical shafts under rotary bending. Fatigue Fracture Eng. Mater. Struct. 21 (18), 1027-1035.

Corwin, W.R., Lucas, G.E. (Eds.), 1986. The Use of Small-scale Specimens for Testing Irradiated Material. ASTM STP888, American Society for Testing and Materials, Albuquerque.

Corwin, W.R., Haggag, F.M., Server, W.L. (Eds.), 1993. Small Specimen Test Techniques Applied to Nuclear Reactor Vessel Thermal Annealing and Plate Life Extension. ASTM STP 1204, American Society for Testing and Materials, New Orleans.

Corwin, W.R., Rosinski, S.T., Van Walle, E. (Eds.), 1997. Small Specimen Test technique. ASTM STP 1329, American Society for Testing and Materials, New Orleans.

De Backer, F., Gutierrez-Solana, F., 1998. The effects of the configuration of a weld-reconstituted compact tension specimen on fracture toughness determination. In: Corwin, W.R., Rosinski, S.T., van Walle, E. (Eds.), Small Specimen Test Techniques. ASTM STP 1329, American Society for Testing and Materials, pp. 436-450.

Fleck, N.A., 1988. Influence of stress state on crack growth retardation. In: Fong, J.T., Fields, R.J. (Eds.), Basic Questions in Fatigue, vol. I. ASTM STP 924, American Society for Testing and Materials, pp. 157-183.
Fleck, N.A., Smith, I.F.C., Smith, R.A., 1983. Closure behaviour of surface cracks. Fatigue Eng. Mater. Struct. 6 (3), 225239.

Haggag, F.M., Server, W.L., Lucas, G.E., Odette, G.R., Sheckherd, J.W., 1990a. The use of miniaturized tests to predict flow properties and estimate fracture toughness in deformed steel plates. J. Test. Eval., JTEVA 1 (1), 62-69.

Haggag, F.M., Nanstad, R.K., Hutton, J.T., Thomas, D.L., Swain, R.L., 1990b. Use of automated ball indentation testing to measure flow properties and estimate fracture toughness in metallic materials. In: Braun, A.A., Ashbaugh, N.E., Smith, F.M. (Eds.), Applications of Automation Technology to Fatigue and Fracture Testing. ASTM STP 1092, American Society for Testing and Materials, Philadelphia, pp. 188-208.

Nishiyama, Y., Fukaya, K., Onizawa, K., Suzuki, M., Nakamura, T., Kaihara, S., Sato, A., Yoshida, K., 1998. Reconstitution of Charpy impact specimens by surface activated joining. In: Corwin, W.R., Rosinski, S.T., van Walle, E. (Eds.), Small Specimen Test Techniques. ASTM STP 1329, American Society for Testing and Materials, pp. 484-494.

Nunomura, S., Noguchi, S., Okamura, Y., Kumai, S., Jitsukawa, S., 1993. Two micro fatigue test methods for irradiated materials. In: Corwin, W.R., Haggag, F.M., Server, W.L. (Eds.), Small Specimen Test Techniques Applied to Nuclear Reactor Vessel Thermal annealing and Plant Life Extension. ASTM STP1204, American Society for Testing and Materials, pp. 275288.

Rao, G.R., Chin, B.A., 1993. Development of a miniature disk bending fatigue specimen. In: Corwin, W.R., Haggag, F.M., Server, W.L. (Eds.), Small Specimen Test Techniques Applied to Nuclear Reactor Vessel Thermal Annealing and Plant Life Extension. ASTM STP1204, American Society for Testing and Materials, pp. 267-274.

Ray, S.K., Perez, R., Grandt Jr., A.F., 1987. Fatigue crack closure of corner cracks located at holes loaded in tension or bending. Fatigue Fracture Eng. Mater. Struct. 10 (3), 239-250.

Shin, C.S., Cai, C.Q., 2004. Stress intensity factor solution for surface cracks in cylindrical rod under tension and bending, in press.

Sriharsha, H.K., Pandey, R.K., Chatterjee, S., 1999. Towards standardising a subsize specimen for fatigue crack propagation behavior of a nuclear pressure vessel. Eng. Fracture Mech. 64, 607-624.

Viehrig, H.W., Boehmert, J., 1998. Specimen reconstitution technique for Charpy size SENB specimens and Charpy-V impact and fracture toughness verification testing. In: Corwin, W.R., Rosinski, S.T., van Walle, E. (Eds.), Small Specimen Test Techniques. ASTM STP 1329, American Society for Testing and Materials, pp. 420-435. 